\title{
Age modulates the effect of COMT genotype on delay discounting behavior
}

\author{
Christopher T. Smith, B.S. ${ }^{1}$ and Charlotte A. Boettiger, Ph.D. ${ }^{1,2}$ \\ ${ }^{1}$ Neurobiology Curriculum Davie Hall, CB \#3270 University of North Carolina Chapel Hill, NC \\ 27599-3270 \\ 2Department of Psychology, Biomedical Research Imaging Center, and Bowles Center for \\ Alcohol Studies Davie Hall, CB \#3270 University of North Carolina Chapel Hill, NC 27599-3270
}

\section{Abstract}

Rationale and objective-A form of impulsivity, the tendency to choose immediate over delayed rewards (delay-discounting) has been associated with a single nucleotide polymorphism (SNP) in the catechol- $O$-methyltransferase (COMT) gene (COMTval ${ }^{158}$ met; rs 4680 ). However, existing data regarding the nature of this association conflicts. We have previously reported that adults homozygous for valine (val) at the COMTval ${ }^{158}$ met SNP demonstrate greater delaydiscounting than do methionine (met) allele carriers (Boettiger et al. 2007). In contrast, a recent study of adolescent males found that those with the met/met genotype demonstrate greater delaydiscounting than do val-allele carriers (Paloyelis et al. 2010). Based on reported age-related changes in frontal dopamine function and COMT expression, we hypothesized that the association of COMT genotype with delay-discounting behavior is modulated by age from late adolescence to young adulthood.

Methods-To test this hypothesis, we genotyped late adolescents (18-21 years; $n=72$ ) and adults (22-40 years; $n=70$ ) for the COMTval ${ }^{158}$ met polymorphism, measured their delay-discounting behavior, and tested for an interaction between age group and COMT genotype.

Results-This cross-sectional study found that age modulates COMTVal ${ }^{158}$ met genotype effects on delay-discounting behavior. Among met-carriers, delay-discounting was negatively correlated with age from late adolescence to adulthood, while among val/val individuals delay-discounting was positively correlated with age across this range.

Conclusions-These results confirm our previous finding of enhanced delay-discounting among $\mathrm{val} / \mathrm{val}$ adults relative to met-allele carriers, and help reconcile existing literature. We propose a single U-shaped model of the relationship between frontal DA levels and impulsive choice that accounts for both adolescent and adult data.

\section{Keywords}

adolescence; decision-making; delay discounting; development; dopamine; impulsivity

Correspondence: Charlotte A. Boettiger, Department of Psychology, Davie Hall, CB \#3270, University of North Carolina, Chapel Hill, NC 27599-3270, Phone: (919) 962-2119, FAX: (919) 962-2537, cab@unc.edu.

CONFLICT OF INTEREST

The authors declare no conflict of interest. 


\section{INTRODUCTION}

Humans and other animals tend to discount the value of delayed, relative to immediate rewards, a phenomenon known as delay-discounting (Ainslie 1975; Frederick et al. 2002; Green and Myerson 2004; Mazur 1987). Delay-discounting is heightened among individuals with a history of substance use disorders (Bickel and Marsch 2001; Reynolds 2006), as well as other impulse control disorders, such as attention deficit/hyperactivity disorder (ADHD) (Paloyelis et al. 2009; Sagvolden and Sergeant 1998; Winstanley et al. 2006). Such immediate reward bias represents one facet of the multi-dimensional construct of impulsivity (Evenden 1999). A variety of evidence links delay-discounting to dopamine (DA) and DA-modulated frontostriatal circuits (Adriani et al. 2009; Altamirano et al. 2011; Boettiger et al. 2007; Doya 2008; Kobayashi and Schultz 2008; Lee et al. 2009; Mitchell et al. 2007; Paloyelis et al. 2010; Pine et al. 2010). Such evidence includes data showing that variation in the gene encoding catechol- $O$-methyltransferase (COMT) is associated with differences in the tendency to choose immediate over delayed rewards (Boettiger et al. 2007; Paloyelis et al. 2010). COMT is an enzyme that regulates DA levels in the prefrontal cortex (Gogos et al. 1998; Kaenmaki et al. 2010; Tunbridge et al. 2004; Yavich et al. 2007), where it is the primary regulator of DA levels (Kaenmaki et al. 2010; Karoum et al. 1994). A polymorphism in the COMT gene (COMTval ${ }^{158}$ met; rs 4680 ) causing a valine (val)-tomethionine (met) substitution at codon 158 results in a 4-fold reduction of COMT enzymatic activity (Lachman et al. 1996), which is presumed to result in reduced cortical DA in val/val homozygotes relative to the met/met genotype (Chen et al. 2004).

We have previously reported that COMTVal ${ }^{158}$ met genotype predicts variation in delaydiscounting behavior in adult humans, including those with a history of alcoholism; specifically, those with the val/val genotype demonstrate greater delay discounting than do met-allele carriers (Boettiger et al. 2007). In contrast, a recent study of male adolescents with and without ADHD found that those with the met/met genotype demonstrate greater delay-discounting than do val-allele carriers (Paloyelis et al. 2010). The sample size in our 2007 study was rather small, thus, in the present study, we sought to confirm our earlier finding in a larger sample. In addition, we sought to determine whether the relationship between COMT genotype and impulsive choice changes from late adolescence to adulthood. Several measures of frontal DA neurotransmission decrease from adolescence to adulthood (see (Wahlstrom et al. 2010) for recent review). Moreover, COMT expression increases with age in humans (Tunbridge et al. 2007), which should contribute to reduced frontal DA signaling from adolescence to adulthood. Behaviors that depend on frontal DA commonly operate within a range of optimal functioning, with both excessive and deficient levels of DA impairing behavioral performance (Goldman-Rakic 1998). Thus, an increase in COMT with age could mean that the low activity COMT genotype could yield an "overdose" of DA in adolescence, but a more optimal level in adulthood, whereas the high activity COMT genotype may compensate for other aspects of enhanced DA signaling in adolescence, but produce a DA deficit in adulthood, as DA signaling declines. Specifically, we hypothesized that the effects of genetically determined variation in COMT function on delay-discounting behavior are oppositely modulated by age, specifically from late adolescence to young adulthood. To test this hypothesis, we genotyped late adolescent and adult participants for the COMTVal ${ }^{158}$ met polymorphism, measured their delay-discounting behavior, and tested for interacting effects of age group and COMT genotype on discounting behavior. As cognitive studies commonly consider participants 18 and over to be adults, we were particularly interested in testing this hypothesis in late adolescents that are frequently assumed to be adults (ages 18-21 years). 


\section{METHODS}

\section{Subjects}

Participants $(n=142)$ were recruited from the University of North Carolina, Chapel Hill (UNC) and surrounding community. Participants were healthy individuals 18-40 years old with no known past or present neurological or psychiatric diagnoses, no history of substance use disorders, and no current use of psychoactive medications or other psychoactive substances aside from moderate caffeine, nicotine or alcohol. All subjects were native English speakers, had at least a high-school education, and reported having consumed alcohol at least once in their lifetime. Participants were recruited into one of two age groups: late adolescents (18-21 years; $n=72$ ) or adults ( $22-40$ years; $n=70$ ). These age group criteria were based on preliminary results from other studies in our lab indicating behavioral differences in our task between these two age groups. This age cutoff is supported by a recent large scale investigation of functional brain maturation that indicated that brain maturation asymptotes at approximately age 22 (Dosenbach et al. 2010). Information regarding participants' personal and parental occupation and education was collected via a questionnaire and quantified as Hollingshead socioeconomic status SES scores (Hollingshead 1975). Participants gave written informed consent, as approved by the UNC Office of Human Research Ethics. Subjects received monetary compensation for participating.

\section{Delay Discounting Task}

The paradigm was based on a previously described task (Altamirano et al. 2011; Boettiger et al. 2007; Mitchell et al. 2005; Mitchell et al. 2007). Briefly, in each session, subjects completed a short ( $\sim 4 \mathrm{~min})$ practice run and then 8 full runs of approximately 42 or 43 trials each ( 7 min). There were four trial types: WANT (W), DON'T WANT (DW), SOONER, and LARGER. Trial types were randomly ordered and weighted such that $50 \%$ were $\mathrm{W}$ condition trials and the remaining trials were evenly divided between the other conditions. Trials began with an instruction cue, followed by two options, each of which was a monetary value and a time. Subjects were asked to evaluate the options as if they would actually receive the specified amounts at the corresponding times. The options consisted of one of five "full" amounts $(\$ 2, \$ 5, \$ 10, \$ 20$, or $\$ 100)$ at one of five future delays (1 week, 2 weeks, 1 month, 3 months, or 6 months) and a discounted amount $(70,85,90$, or $95 \%$ of the "full" amount) offered at no delay ("TODAY").

Subjects were instructed to make a choice in each trial, according to the trial type: preferred option on W trials, non-preferred option on DW trials, and the side with the sooner time or larger amount of money for SOONER and LARGER trials, respectively. These latter two conditions are considered together as control ("CON") trials. The order of trial types was the same for all subjects; however, the delayed amount, delay time, and discount were pseudorandomly ordered.

The length of the task ( $\sim 56 \mathrm{~min})$ could raise the concern that choice behavior is affected by fatigue or other temporally-dependent effects. This could be a particular concern if such effects varied with age or genotype. These concerns can be dismissed on the basis of the following analyses. First, a repeated measures ANOVA found no significant effect of block number on ICR $\left(F_{7,917)}=0.49, p=0.84\right)$, nor any significant ICR by block interaction with age $\left(F_{(7,917)}=0.31, p=0.95\right)$ or genotype $\left(F_{(14,917)}=0.22, p=1\right)$. Second, when we calculated the split-half ICR for odd and even blocks, the correlation across all subjects was $r=0.98(p<0.001)$. Similarly, the correlation between first half ICR and second half ICR was $r=0.96$ ( $p<0.001)$. Finally, for the sample as a whole, Cronbach's $a=0.99$.

Furthermore, Cronbach's a was also 0.99 when calculated separately for each age group and 
each genotype. We note that these reliability measures are well above the standard criterion for adequate reliability of 0.70 (Kline 2000).

\section{Genotyping}

COMTval ${ }^{158}$ met (rs4680) genotyping was performed on DNA extracted from saliva samples (DNA Genotek, Kanata, Ontario, Canada) using TaqMan technology (Applied Biosystems, Foster City, CA), as described previously (Boettiger et al. 2007). Genotyping was performed by the UNC Mammalian Genotyping Core and/or the Duke Center for Human Genetics. Genotyping was performed in duplicate for $n=42$ samples and compared to ensure validity of the data. The genotype concordance rate was $100 \%$ both within $(n=42)$ and across $(\mathrm{n}=32)$ genotyping facilities. Allele frequencies in this sample did not deviate from Hardy-Weinberg equilibrium $\left(\chi^{2}=0.098, \mathrm{df}=2, p=0.95\right)$.

\section{Data Analysis}

Our index of temporal discounting was the proportion of "TODAY" choices in W trials, which we have termed the impulsive choice ratio (ICR). Although this value was calculated separately according to delay time and delayed amount, here we focus on the ratio collapsed across all $\mathrm{W}$ trials.

To test the significance of across group comparisons, we used unpaired two-tailed $t$-tests for continuous measures and $\chi^{2}$ tests for categorical measures. For multi-factorial comparisons, we used regular or mixed repeated measures ANOVA in SPSS (SPSS Inc., Chicago, IL), with age group and genotype as between subjects factors. When necessary, a GreenhouseGeisser non-sphericity correction was applied. Post-hoc paired comparisons were performed where indicated using two-tailed $t$-tests. When data were not normally distributed, appropriate arcsine-root transformations were applied in Excel (Microsoft Corp., Redmond, WA) prior to making statistical comparisons to ensure the validity of parametric statistical tests. Simple regression analyses were performed in SPSS.

\section{RESULTS}

\section{Demographic and psychometric data}

To test whether COMTVal ${ }^{158}$ met genotype differentially predicts ICR among late adolescents versus adults, we genotyped two groups of subjects: late adolescents (18-21 years; $n=72$ ) and adults ( $22-40$ years; $n=70)$. There were no significant differences between the two groups in terms of gender, ethnicity, or parental socio-economic status (SES; see Table 1). As expected, the late adolescent group was significantly younger than the adult group, and also reported lower personal SES levels (driven primarily by a lower level of education), and slightly greater alcohol use (AUDIT score) than did the adult group (Table 1).

\section{Interaction between age and COMT genotype on frequency of impulsive choices}

On the basis of COMTVal ${ }^{158}$ met genotype, participants were subdivided into methomozygotes (met/met; $n=33$ ), heterozygotes (val/met; $n=69$ ) and val/val homozygote individuals $(n=40)$. COMT genotype groups did not differ significantly in terms of demographic features (education, age, sex, ethnicity, SES, and alcohol use), or task performance (reaction times and control trial accuracy; Table 2). On the basis of our a priori hypothesis for an agexgenotype interaction in delay-discounting behavior, we conducted a factorial ANOVA with age group and COMTVal ${ }^{158}$ met genotype as between-subjects factors, taking an index of delay-discounting, the impulsive choice ratio (ICR; see Methods), as the dependent measure. Although our groups were matched for sex (Tables 1 and 2), we included sex as a factor in our analyses as a means of detecting sexually dimorphic effects of 
COMT on delay discounting, as sex-dependent effects on COMT enzyme activity have been reported (Chen et al. 2004). We included SES and alcohol use (AUDIT score) as covariates due to the fact that we observed significant differences in SES and AUDIT scores between our age groups (Table 1).

In a $2 \times 2 \times 3$ ANOVA (age group $\times$ COMT genotype $\times$ sex), we did not detect significant main effects of age group $\left(F_{(1,128)}=0.68, p=0.411, \eta^{2}=0.005\right)$, COMTVal $^{158}$ met genotype $\left(F_{(2,128)}=0.08, p=0.921, \eta^{2}=0.001\right)$ or $\operatorname{sex}\left(F_{(1,128)}=1.33, p=0.252, \eta^{2}=\right.$ 0.009) on ICR. Moreover, we observed no significant interaction between sex and COMT genotype $\left(F_{(2,128)}=0.86, p=0.424, \eta^{2}=0.012\right)$, or three-way interaction between sex, COMT genotype, and age group $\left(F_{(2,128)}=0.42, p=0.658, \eta^{2}=0.006\right)$. In contrast, consistent with our hypothesis, there was a significant age-by-COMTVal ${ }^{158}$ met interaction effect on delay-discounting behavior. $\left(F_{(2,128)}=5.15, p=0.007, \eta^{2}=0.069\right.$; Figure 1$)$. We also detected a smaller interactive effect between sex and age-group $\left(F_{(1,128)}=4.08, p=\right.$ $0.046, \eta^{2}=0.027$ ). Given our somewhat ethnically mixed sample (see Tables 1 and 2 ) and the reported racial differences in COMTVal ${ }^{158}$ met allele frequencies (e.g. (McLeod et al. 1994; McLeod et al. 1998), it is worth noting that the age-by-COMTVal ${ }^{158}$ met interaction was also seen in our white participants, the largest ethnic group included $\left(F_{(2,83)}=12.51, p\right.$ $\left.<0.001, \eta^{2}=0.216\right)$. Among non-white participants, we observed a similar, albeit nonsignificant, trend $\left(F_{(2,43)}=1.68, p=0.198, \eta^{2}=0.066\right)$, likely due to the heterogeneity within this smaller group. This interaction effect reflects a significant age-related increase in delay-discounting among val-homozygotes $\left(t_{(38)}=2.48, p=0.018\right)$ and a significant agerelated decline in delay-discounting among both met-homozygotes $\left(t_{(31)}=2.20, p=0.036\right)$ and COMTVal ${ }^{158}$ met heterozygotes $\left(t_{(67)}=2.01, p=0.048\right)$. Considering age as a continuous variable, we observed a negative correlation between age and ICR among metallele carriers $(r=-0.31, p=0.001)$. In contrast, among val/val individuals we observed a significant positive correlation between age and ICR $(r=0.32, p=0.047)$.

While we have previously reported that choice behavior in this task does not correlate with education or SES (Mitchell et al. 2005; Mitchell et al. 2007), the present study included a somewhat younger demographic. Thus, we carried out bivariate correlations to assess whether demographic factors predicted decision-making behavior in this cohort of participants. We found that the tendency to choose a smaller immediate reward did not correlate with years of education $(r=-0.09, t=-1.04, p=0.299)$. Similarly, SES was not significantly correlated with ICR $(r=-0.14, t=-1.66, p=0.1)$. We also observed no correlation between age and ICR $(r=-0.14, t=-1.62, p=0.107)$, which is not unexpected based on the opposing age effects for met-carriers and val homozygotes.

The mean overall ICR values (shown in Figure 1), including SD, were as follows for the Late Adolescent group: val/val, $0.56 \pm 0.39$; val/met, $0.70 \pm 0.24$; met/met, $0.70 \pm 0.28$. Corresponding values for the Adult group were: val/val, $0.79 \pm 0.21$; val/met, $0.57 \pm 0.31$; $\mathrm{met} / \mathrm{met}, 0.45 \pm 0.32$. We have previously reported that discounting in this task is modulated by reward magnitude (Mitchell et al. 2005; Mitchell et al. 2007), such that participants show greater discounting for smaller rewards. This finding was replicated in the present study (Figure 2 ) as shown by a 3 -way ANOVA (delayed reward amount $\times$ age group $\times$ genotype), which found a significant main effect of delayed reward amount $\left(F_{(2.15,292.96)}=146.24, p<\right.$ $\left.0.001, \eta^{2}=0.512\right)$. We did not observe significant interactions between delayed reward amount and either age group $\left.\left(F_{(2.15}, 292.96\right)=0.79, p=0.465, \eta^{2}=0.003\right)$ or genotype $\left(F_{(4.31,292.96)}=0.67, p=0.624, \eta^{2}=0.005\right)$. Likewise, we observed no significant threeway interaction $\left(F_{(4.31,292.96)}=0.66, p=0.632, \eta^{2}=0.005\right)$. Thus the genotype $\times$ age group interaction that we observed does not appear to be specific to certain magnitudes of reward. 


\section{DISCUSSION}

The present results confirm our previous finding of enhanced delay-discounting among COMTval ${ }^{158}$ met val/val adults relative to met-allele carriers (Boettiger et al. 2007).

Moreover, these results help account for the discrepancy between our earlier findings and the results of Paloyelis et al. (2010) showing enhanced delay-discounting among COMTval ${ }^{158}$ met met/met adolescent males. Furthermore, as our study included females and found no main effect of sex, nor any interaction of sex with our genotype by age effect, these data extend the previous finding in adolescent males of Paloyelis et al. (2010) to late adolescent females.

\section{Relationship between alcohol use and delay-discounting}

We previously found a significant positive relationship between ICR and alcohol use in studies including both control subjects and those with a history of alcoholism (Boettiger et al. 2007; Mitchell et al. 2005; Mitchell et al. 2007). We have also reported a positive correlation between ICR and the dependence and harm subscales of the AUDIT (Mitchell et al. 2005). However, consistent with the present data, we have not found a significant relationship between ICR and AUDIT scores in studies restricted to those with no history of alcoholism (Altamirano et al. 2011). This discrepancy may reflect inadequate power to detect an effect due to insufficient variance in AUDIT dependence and harm scores in samples excluding AUDs. For example, the median AUDIT dependence and harm score here was 2 (interquartile range: 1 - 4.75). In contrast, the median in Mitchell, et al. (2005) was the same, but the interquartile range was more $>3 \times \operatorname{larger}(0.75-16)$. Alternatively, the relationship between ICR and AUDIT may be weak.

\section{Cortical dopamine regulation of delay-discounting}

Consistent with our hypothesis, we found that age modulates COMTVal ${ }^{158}$ met genotype effects on delay-discounting behavior. Adult met-allele carriers showed significantly less delay-discounting relative to late adolescent met-carriers, while val/val adults showed significantly more delay-discounting relative to late adolescent val/val individuals. To account for both the adolescent and adult data we report, we propose a single U-shaped model of the relationship between frontal DA levels and impulsive choice (Figure 3). Such a model is supported by evidence that dopaminergic modulation of frontal functions often follows a U-shaped curve, where deficient or excess DA can impair frontal functioning (Arnsten 1997; Goldman-Rakic et al. 2000; Williams and Castner 2006; Zahrt et al. 1997). Our model posits that reduced frontal DA signaling in adulthood relative to late adolescence results in opposing effects on impulsive choice in different COMT genotypes, based on this U-shaped relationship. Specifically, an age-dependent drop in frontal DA signaling in val/ val individuals yields greater ICR in adults relative to adolescents. In contrast, an equivalent age-dependent drop in frontal DA signaling results in reduced delay-discounting in metcarrier adults relative to adolescents. For simplicity, we have proposed equivalent declines in frontal DA signaling across COMT genotypes; however, developmental declines in frontal DA signaling may vary by COMT genotype. Support for this possibility comes from recent data showing COMTVal ${ }^{158}$ met genotype-dependent methylation resulting in reduced val allele expression (Ursini et al. 2011). Developmental regulation of methylation is one mechanism by which declines in frontal DA signaling could vary by COMT genotype. An important prediction of this model is that within typical "healthy young adult" samples (ages 18-40), the admixture of late adolescents and young adults would tend to obscure COMT genotype effects. While this model is currently hypothetical, future PET studies may test the validity of this U-shape model of the effects of age-dependent differences in frontal DA signaling on impulsive choice. 
One remaining important question is whether age-dependent differences in COMT genotype effects on decision-making behavior differ among different ethnic groups. While the present data conclusively find an age by COMT genotype interaction among white participants, they lack sufficient power to draw this same conclusion for other ethnic groups. Heterogeneity within the non-white sample may contribute to this lack of power. Moreover, the relationship between age and discounting behavior could vary with ethnicity, introducing another source of variance. Larger explicit studies of the effects of ethnicity may resolve this question.

\section{Broader implications of age-dependent differences in COMT genotype effects}

In addition to playing a role in modulating impulsive choice, the val/val genotype is also associated with poorer performance on executive tasks and greater frontal activation relative to met-carriers (Blasi et al. 2005; Egan et al. 2001; Minzenberg et al. 2006; Tan et al. 2007; Winterer et al. 2006a; Winterer et al. 2006b), which is thought to reflect frontal processing inefficiency, particularly during tasks requiring maintenance of stable representations (Bilder et al. 2004; Nolan et al. 2004; Tunbridge et al. 2006). However, published data regarding the role of the COMTVal ${ }^{158}$ met genotype in cognition is mixed (Barnett et al. 2008; Dennis et al. 2010). Thus, in addition to reconciling the literature regarding the effect of COMTVal ${ }^{158}$ met genotype on delay-discounting behavior, these data also suggest an explanation for discrepancies in the literature regarding COMT genotype effects on executive function.

We note that the present study was cross-sectional in nature; a prospective study is required to determine whether the age modulation of COMT genotype effects on delay-discounting reflects developmental processes. Such processes may specifically affect delay-discounting behavior or may also impact linked behaviors, such as working memory (Shamosh and Gray 2008; Shamosh et al. 2008). Specificity of underlying neural circuits may result in taskdependent sensitivity to frontal DA levels, whereby the optimal level for certain tasks is suboptimal for other tasks (Cools and Robbins 2004; Nolan et al. 2004). Moreover, frontal circuit maturation remains incomplete until the early-to-mid twenties (Sowell et al., 1999; Casey et al., 2000; Sowell et al., 2001; Giedd, 2004; Gogtay et al., 2004; Lenroot and Giedd, 2006), and components of this circuitry critical for particular tasks may mature at different rates.

\section{Implications for effects of manipulating DA signaling}

As noted earlier, several measures of frontal DA signaling decrease from adolescence to adulthood (see (Wahlstrom et al. 2010) for recent review). COMT expression increases across the lifespan in humans (Tunbridge et al. 2007), which should result in an agedependent decrement in frontal DA. An important implication of the age-dependent differences in COMT genotype effects on delay-discounting is that accounting for both age and COMT genotype may be required to accurately predict the effects of medications that alter frontal DA. Relevant clinical disorders are those associated with impaired frontal DA function, such as schizophrenia, addiction, and ADHD. As these disorders frequently onset in late adolescence (or sooner, in the case of ADHD), understanding how age may impact medication response could help to optimize clinical outcomes for these conditions.

\section{Study limitations}

A limitation of the present study is that it cannot completely reconcile the differences between the findings of Paloyelis et al. (2010) and Boettiger et al. (2007), since the adolescent group in the present study did not include participants younger than 18, as did that of Paloyelis and colleagues. Another limitation is the lack of investigation of other genetic variations that may impact delay-discounting behavior, a substantially heritable trait 
(Anokhin et al. 2011; Mitchell 2011). For example, the DA $\mathrm{D}_{4}$ receptor (DRD4) and $\mathrm{D}_{2}$ receptor (DRD2) genes have been linked to variation in delay-discounting behavior (Eisenberg et al. 2007), although these findings are not unequivocal (Paloyelis et al. 2010; White et al. 2009; White et al. 2008). As such it is important to consider these results primarily as further evidence that proxy indicators of frontal DA signaling can predict some of the individual differences in delay-discounting. In addition, our results highlight the importance of considering age as a possible confounding factor in future studies evaluating genetic contributions to delay-discounting behavior. Future studies designed to test for interactions between COMT and other polymorphisms in adults may help to clarify the interacting roles for frontal and striatal DA signaling in regulating delay discounting behavior; such studies will also require larger sample sizes than that reported here. Beyond age, we did not find additional environmental variables that accounted for substantial variance in discounting behavior within our sample. However, future larger-scale studies that explicitly test for effects of alcohol use, gender, as well as related cognitive phenotypes may allow for a more complete understanding of the neurobiology of discounting behavior. In particular, measures of working memory, reward sensitivity, and response inhibition may each be regulated by separate DA-regulated networks, which in turn make differing contributions to delay-discounting behavior.

\section{Acknowledgments}

This work was supported by Award Numbers UL1RR025747 and KL2RR025746 (CAB) from the National Center for Research Resources and by T32NS007431 and F31AA020132 (CTS). The authors thank R. Bigler, A. Desai, E. Freeman-Daniels, C. Lang, N. Le, J. Lopez, and E. Steel for technical assistance.

\section{References}

Adriani W, Boyer F, Gioiosa L, Macri S, Dreyer JL, Laviola G. Increased impulsive behavior and risk proneness following lentivirus-mediated dopamine transporter over-expression in rats' nucleus accumbens. Neuroscience. 2009; 159:47-58. [PubMed: 19135135]

Ainslie G. Specious reward: a behavioral theory of impulsiveness and impulse control. Psychol Bull. 1975; 82:463-96. [PubMed: 1099599]

Altamirano LJ, Fields HL, D’Esposito M, Boettiger CA. Interaction between Family History of Alcoholism and Locus of Control in the Opioid Regulation of Impulsive Responding under the Influence of Alcohol. Alcohol Clin Exp Res. 2011; 35:1905-1914. [PubMed: 21569055]

Anokhin A, Golosheykin S, Grant J, Heath A. Heritability of Delay Discounting in Adolescence: A Longitudinal Twin Study. Behavior Genetics. 2011; 41:175-183. [PubMed: 20700643]

Arnsten AF. Catecholamine regulation of the prefrontal cortex. J Psychopharmacol. 1997; 11:151-62. [PubMed: 9208378]

Barnett JH, Scoriels L, Munafo MR. Meta-analysis of the cognitive effects of the catechol-Omethyltransferase gene Val158/108Met polymorphism. Biol Psychiatry. 2008; 64:137-44. [PubMed: 18339359]

Bickel WK, Marsch LA. Toward a behavioral economic understanding of drug dependence: delay discounting processes. Addiction. 2001; 96:73-86. [PubMed: 11177521]

Bilder RM, Volavka J, Lachman HM, Grace AA. The catechol-O-methyltransferase polymorphism: relations to the tonic-phasic dopamine hypothesis and neuropsychiatric phenotypes. Neuropsychopharmacology. 2004; 29:1943-61. [PubMed: 15305167]

Blasi G, Mattay VS, Bertolino A, Elvevag B, Callicott JH, Das S, Kolachana BS, Egan MF, Goldberg TE, Weinberger DR. Effect of catechol-O-methyltransferase val158met genotype on attentional control. J Neurosci. 2005; 25:5038-45. [PubMed: 15901785]

Boettiger CA, Mitchell JM, Tavares VC, Robertson M, Joslyn G, D’Esposito M, Fields HL. Immediate reward bias in humans: fronto-parietal networks and a role for the catechol-O-methyltransferase 158(Val/Val) genotype. J Neurosci. 2007; 27:14383-91. [PubMed: 18160646] 
Chen J, Lipska BK, Halim N, Ma QD, Matsumoto M, Melhem S, Kolachana BS, Hyde TM, Herman MM, Apud J, Egan MF, Kleinman JE, Weinberger DR. Functional analysis of genetic variation in catechol-O-methyltransferase (COMT): effects on mRNA, protein, and enzyme activity in postmortem human brain. Am J Hum Genet. 2004; 75:807-21. [PubMed: 15457404]

Cools R, Robbins TW. Chemistry of the adaptive mind. Philos Transact A Math Phys Eng Sci. 2004; 362:2871-88. [PubMed: 15539374]

Dennis NA, Need AC, LaBar KS, Waters-Metenier S, Cirulli ET, Kragel J, Goldstein DB, Cabeza R. COMT val108/158 met genotype affects neural but not cognitive processing in healthy individuals. Cereb Cortex. 2010; 20:672-83. [PubMed: 19641018]

Dosenbach NU, Nardos B, Cohen AL, Fair DA, Power JD, Church JA, Nelson SM, Wig GS, Vogel AC, Lessov-Schlaggar CN, Barnes KA, Dubis JW, Feczko E, Coalson RS, Pruett JR Jr, Barch DM, Petersen SE, Schlaggar BL. Prediction of individual brain maturity using fMRI. Science. 2010; 329:1358-61. [PubMed: 20829489]

Doya K. Modulators of decision making. Nat Neurosci. 2008; 11:410-6. [PubMed: 18368048]

Egan MF, Goldberg TE, Kolachana BS, Callicott JH, Mazzanti CM, Straub RE, Goldman D, Weinberger DR. Effect of COMT Val108/158 Met genotype on frontal lobe function and risk for schizophrenia. Proc Natl Acad Sci U S A. 2001; 98:6917-22. [PubMed: 11381111]

Eisenberg D, MacKillop J, Modi M, Beauchemin J, Dang D, Lisman S, Lum JK, Wilson D. Examining impulsivity as an endophenotype using a behavioral approach: a DRD2 TaqI A and DRD4 48-bp VNTR association study. Behavioral and Brain Functions. 2007; 3:2. [PubMed: 17214892]

Evenden JL. Varieties of impulsivity. Psychopharmacology (Berl). 1999; 146:348-61. [PubMed: 10550486]

Frederick S, Loewenstein G, O’Donoghue T. Time discounting and time preference: A critical review. J Economic Literature. 2002; 40:351-401.

Gogos JA, Morgan M, Luine V, Santha M, Ogawa S, Pfaff D, Karayiorgou M. Catechol-Omethyltransferase-deficient mice exhibit sexually dimorphic changes in catecholamine levels and behavior. Proc Natl Acad Sci U S A. 1998; 95:9991-6. [PubMed: 9707588]

Goldman-Rakic PS. The cortical dopamine system: role in memory and cognition. Adv Pharmacol. 1998; 42:707-11. [PubMed: 9327997]

Goldman-Rakic PS, Muly EC 3rd, Williams GV. D(1) receptors in prefrontal cells and circuits. Brain Res Brain Res Rev. 2000; 31:295-301. [PubMed: 10719156]

Green L, Myerson J. A discounting framework for choice with delayed and probabilistic rewards. Psychol Bull. 2004; 130:769-92. [PubMed: 15367080]

Hollingshead, A. Hollingshead's Four Factor Index of Social Status. Yale University Press, Yale University Press; 1975.

Kaenmaki M, Tammimaki A, Myohanen T, Pakarinen K, Amberg C, Karayiorgou M, Gogos JA, Mannisto PT. Quantitative role of COMT in dopamine clearance in the prefrontal cortex of freely moving mice. J Neurochem. 2010; 114:1745-55. [PubMed: 20626558]

Karoum F, Chrapusta SJ, Egan MF. 3-Methoxytyramine is the major metabolite of released dopamine in the rat frontal cortex: reassessment of the effects of antipsychotics on the dynamics of dopamine release and metabolism in the frontal cortex, nucleus accumbens, and striatum by a simple two pool model. J Neurochem. 1994; 63:972-9. [PubMed: 7914228]

Kline, P. The handbook of psychological testing. 2. Routledge, Routledge; 2000.

Kobayashi S, Schultz W. Influence of reward delays on responses of dopamine neurons. J Neurosci. 2008; 28:7837-46. [PubMed: 18667616]

Lachman HM, Papolos DF, Saito T, Yu YM, Szumlanski CL, Weinshilboum RM. Human catechol-Omethyltransferase pharmacogenetics: description of a functional polymorphism and its potential application to neuropsychiatric disorders. Pharmacogenetics. 1996; 6:243-50. [PubMed: 8807664]

Lee B, London ED, Poldrack RA, Farahi J, Nacca A, Monterosso JR, Mumford JA, Bokarius AV, Dahlbom M, Mukherjee J, Bilder RM, Brody AL, Mandelkern MA. Striatal dopamine d2/d3 receptor availability is reduced in methamphetamine dependence and is linked to impulsivity. $\mathrm{J}$ Neurosci. 2009; 29:14734-40. [PubMed: 19940168]

Mazur, JE. Quantitative Analyses of Behavior. Hillsdale, NJ: 1987. An adjusting procedure for studying delayed reinforcement. 
McLeod HL, Fang L, Luo X, Scott EP, Evans WE. Ethnic differences in erythrocyte catechol-Omethyltransferase activity in black and white Americans. J Pharmacol Exp Ther. 1994; 270:26-9. [PubMed: 8035323]

McLeod HL, Syvanen AC, Githang'a J, Indalo A, Ismail D, Dewar K, Ulmanen I, Sludden J. Ethnic differences in catechol O-methyltransferase pharmacogenetics: frequency of the codon 108/158 low activity allele is lower in Kenyan than Caucasian or South-west Asian individuals. Pharmacogenetics. 1998; 8:195-9. [PubMed: 9682265]

Minzenberg MJ, Xu K, Mitropoulou V, Harvey PD, Finch T, Flory JD, New AS, Goldman D, Siever LJ. Catechol-O-methyltransferase Val158Met genotype variation is associated with prefrontaldependent task performance in schizotypal personality disorder patients and comparison groups. Psychiatr Genet. 2006; 16:117-24. [PubMed: 16691129]

Mitchell JM, Fields HL, D’Esposito M, Boettiger CA. Impulsive responding in alcoholics. Alcohol Clin Exp Res. 2005; 29:2158-69. [PubMed: 16385186]

Mitchell JM, Tavares VC, Fields HL, D’Esposito M, Boettiger CA. Endogenous opioid blockade and impulsive responding in alcoholics and healthy controls. Neuropsychopharmacology. 2007; 32:439-49. [PubMed: 17047667]

Mitchell SH. The genetic basis of delay discounting and its genetic relationship to alcohol dependence. Behavioural Processes. 2011; 87:10-17. [PubMed: 21354276]

Nolan KA, Bilder RM, Lachman HM, Volavka J. Catechol O-methyltransferase Val158Met polymorphism in schizophrenia: differential effects of Val and Met alleles on cognitive stability and flexibility. Am J Psychiatry. 2004; 161:359-61. [PubMed: 14754787]

Paloyelis Y, Asherson P, Kuntsi J. Are ADHD symptoms associated with delay aversion or choice impulsivity? A general population study. J Am Acad Child Adolesc Psychiatry. 2009; 48:837-46. [PubMed: 19564796]

Paloyelis Y, Asherson P, Mehta MA, Faraone SV, Kuntsi J. DAT1 and COMT effects on delay discounting and trait impulsivity in male adolescents with attention deficit/hyperactivity disorder and healthy controls. Neuropsychopharmacology. 2010; 35:2414-26. [PubMed: 20736997]

Pine A, Shiner T, Seymour B, Dolan RJ. Dopamine, Time, and Impulsivity in Humans. J Neurosci. 2010; 30:8888-8896. [PubMed: 20592211]

Reynolds B. A review of delay-discounting research with humans: relations to drug use and gambling. Behav Pharmacol. 2006; 17:651-67. [PubMed: 17110792]

Sagvolden T, Sergeant JA. Attention deficit/hyperactivity disorder--from brain dysfunctions to behaviour. Behav Brain Res. 1998; 94:1-10. [PubMed: 9708834]

Shamosh N, Gray J. Delay discounting and intelligence: A meta-analysis. Intelligence. 2008; 38:289305.

Shamosh NA, Deyoung CG, Green AE, Reis DL, Johnson MR, Conway AR, Engle RW, Braver TS, Gray JR. Individual differences in delay discounting: relation to intelligence, working memory, and anterior prefrontal cortex. Psychol Sci. 2008; 19:904-11. [PubMed: 18947356]

Tan HY, Chen Q, Goldberg TE, Mattay VS, Meyer-Lindenberg A, Weinberger DR, Callicott JH. Catechol-O-methyltransferase Val158Met modulation of prefrontal-parietal-striatal brain systems during arithmetic and temporal transformations in working memory. J Neurosci. 2007; 27:13393401. [PubMed: 18057197]

Tunbridge EM, Bannerman DM, Sharp T, Harrison PJ. Catechol-o-methyltransferase inhibition improves set-shifting performance and elevates stimulated dopamine release in the rat prefrontal cortex. J Neurosci. 2004; 24:5331-5. [PubMed: 15190105]

Tunbridge EM, Harrison PJ, Weinberger DR. Catechol-o-methyltransferase, cognition, and psychosis: Val158Met and beyond. Biol Psychiatry. 2006; 60:141-51. [PubMed: 16476412]

Tunbridge EM, Weickert CS, Kleinman JE, Herman MM, Chen J, Kolachana BS, Harrison PJ, Weinberger DR. Catechol-o-methyltransferase enzyme activity and protein expression in human prefrontal cortex across the postnatal lifespan. Cereb Cortex. 2007; 17:1206-12. [PubMed: 16835293]

Ursini G, Bollati V, Fazio L, Porcelli A, Iacovelli L, Catalani A, Sinibaldi L, Gelao B, Romano R, Rampino A, Taurisano P, Mancini M, Di Giorgio A, Popolizio T, Baccarelli A, De Blasi A, Blasi G, Bertolino A. Stress-Related Methylation of the Catechol-O-Methyltransferase Val158 Allele 
Predicts Human Prefrontal Cognition and Activity. J Neurosci. 2011; 31:6692-6698. [PubMed: 21543598]

Wahlstrom D, Collins P, White T, Luciana M. Developmental changes in dopamine neurotransmission in adolescence: behavioral implications and issues in assessment. Brain Cogn. 2010; 72:146-59. [PubMed: 19944514]

White M, Lawford B, Morris C, Young R. Interaction Between DRD2 C957T Polymorphism and An Acute Psychosocial Stressor on Reward-Related Behavioral Impulsivity. Behavior Genetics. 2009; 39:285-295. [PubMed: 19148742]

White M, Morris CP, Lawford B, Young R. Behavioral phenotypes of impulsivity related to the ANKK1 gene are independent of an acute stressor. Behavioral and Brain Functions. 2008; 4:54. [PubMed: 19025655]

Williams GV, Castner SA. Under the curve: critical issues for elucidating D1 receptor function in working memory. Neuroscience. 2006; 139:263-76. [PubMed: 16310964]

Winstanley CA, Eagle DM, Robbins TW. Behavioral models of impulsivity in relation to ADHD: translation between clinical and preclinical studies. Clin Psychol Rev. 2006; 26:379-95. [PubMed: 16504359]

Winterer G, Egan MF, Kolachana BS, Goldberg TE, Coppola R, Weinberger DR. Prefrontal electrophysiologic "noise" and catechol-O-methyltransferase genotype in schizophrenia. Biol Psychiatry. 2006a; 60:578-84. [PubMed: 16730334]

Winterer G, Musso F, Vucurevic G, Stoeter P, Konrad A, Seker B, Gallinat J, Dahmen N, Weinberger DR. COMT genotype predicts BOLD signal and noise characteristics in prefrontal circuits. Neuroimage. 2006b; 32:1722-32. [PubMed: 16884927]

Yavich L, Forsberg MM, Karayiorgou M, Gogos JA, Mannisto PT. Site-specific role of catechol-Omethyltransferase in dopamine overflow within prefrontal cortex and dorsal striatum. J Neurosci. 2007; 27:10196-209. [PubMed: 17881525]

Zahrt J, Taylor JR, Mathew RG, Arnsten AF. Supranormal stimulation of D1 dopamine receptors in the rodent prefrontal cortex impairs spatial working memory performance. J Neurosci. 1997; 17:8528-35. [PubMed: 9334425] 

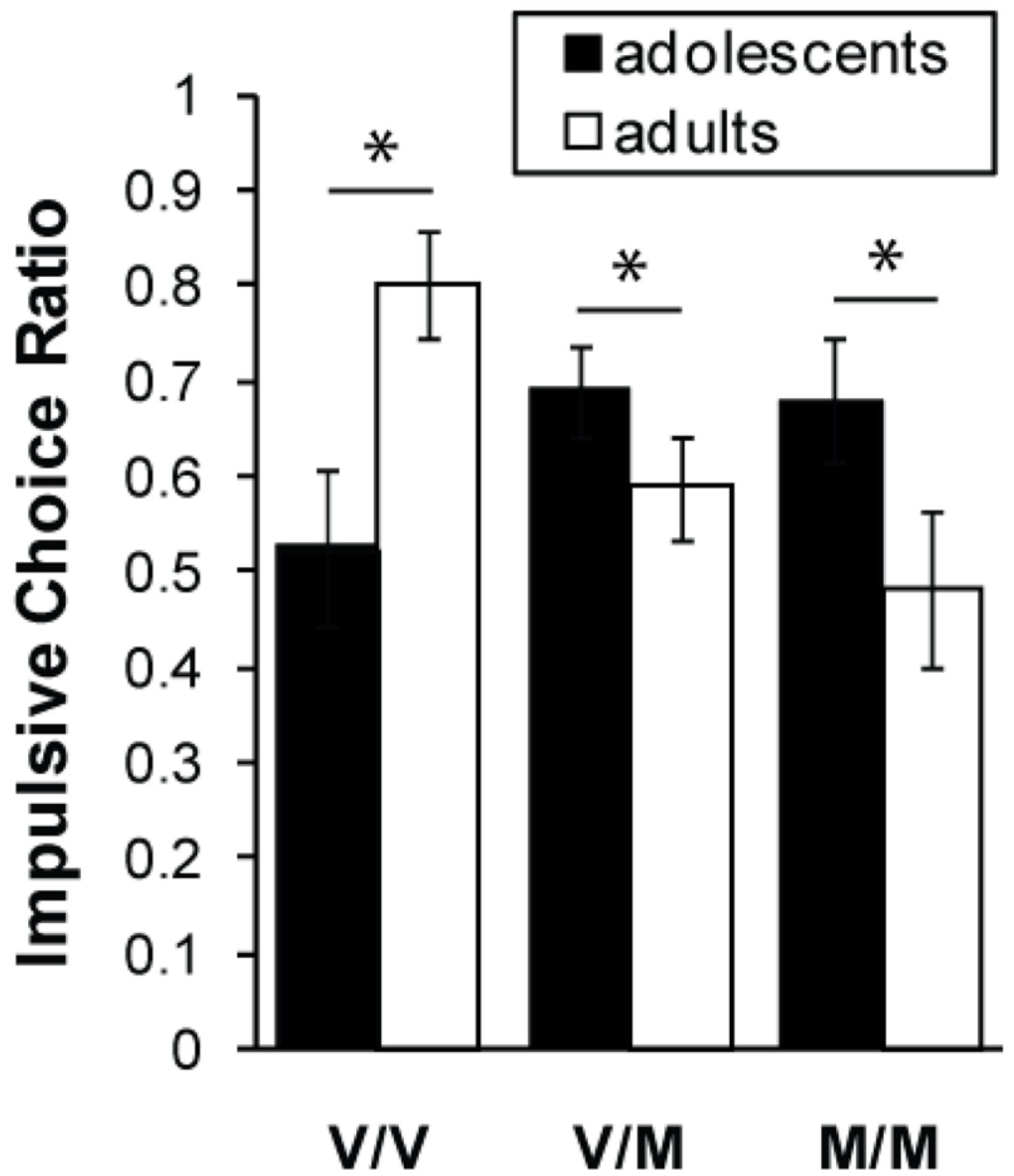

$\mathrm{V} / \mathrm{M}$

$M / M$

\section{COMT genotype}

Figure 1.

Age interacts with COMT genotype to influence impulsive decision-making. (a) Plot of impulsive choice ratio (ICR) as a function of COMT genotype, showing a significant age by genotype interaction $\left(\mathrm{F}_{(2,134)}=7.13, \mathrm{p}=0.001\right)$. This effect reflects significant age-related changes in ICR for all three genotypes. M/M, methionine/methionine; V/M, valine/ methionine; V/V, valine/valine. ${ }^{*} p<0.05$. 


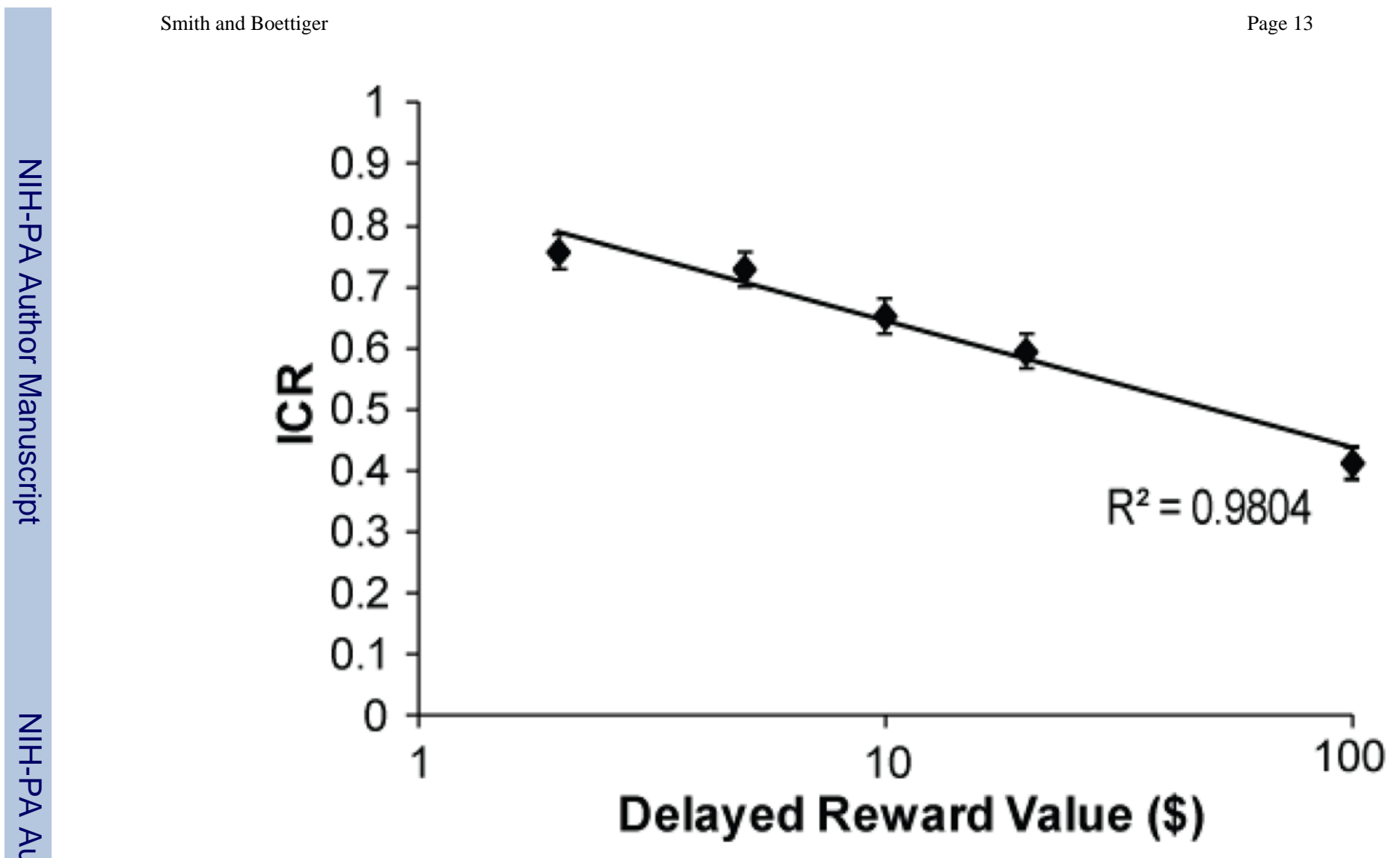

Figure 2.

Comparison of reward magnitude discounting functions. Semi-log plot of ICR as a function of the delayed reward amount. Data reflect mean \pm SEM. Curves represent logarithmic fit the group averaged data. 


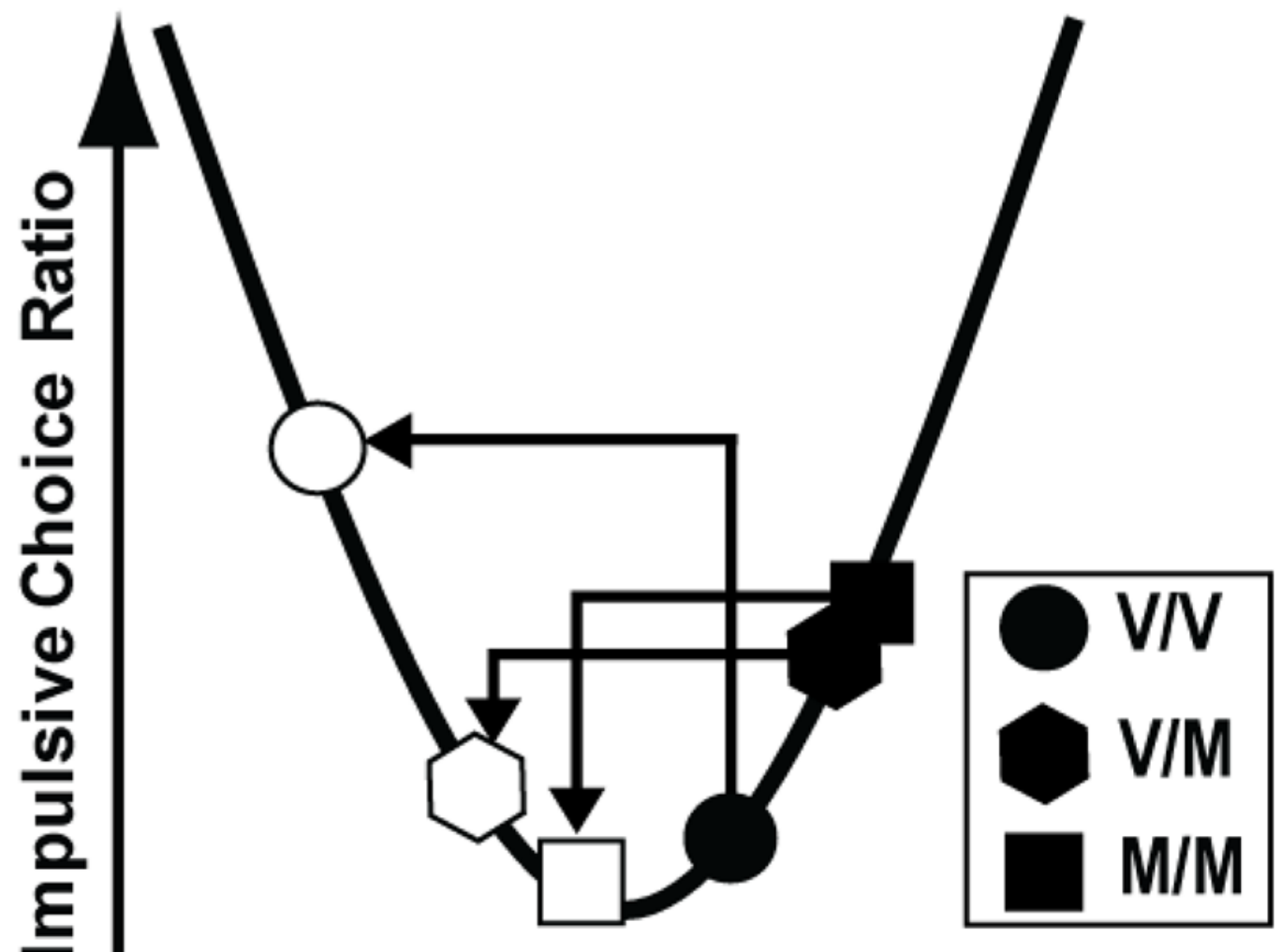

Frontal DA

Figure 3.

Model depicting hypothetical regulation of impulsive choice by frontal dopamine. Closed symbols represent adolescents, whole open symbols represent adults. Arrows indicate the effects of a developmental decline in frontal dopamine function for each genotype. Model posits that reduced frontal DA signaling in adulthood relative to late adolescence results in opposing effects on impulsive choice that vary with COMT genotype, based on an underlying U-shaped relationship. An age-dependent drop in frontal DA signaling in val/val individuals is predicted to yield greater ICR in adults relative to adolescents. In contrast, an equivalent age-dependent drop in frontal DA signaling is predicted to result in reduced ICR in met-carrier adults relative to adolescents. For simplicity, equivalent declines in frontal DA signaling are proposed for all COMT genotypes, although differential changes may occur. COMT, catechol- $O$-methyltransferase; DA, dopamine; M/M, methionine/methionine; $\mathrm{V} / \mathrm{M}$, valine/methionine; $\mathrm{V} / \mathrm{V}$, valine/valine. 
Table 1

Demographic data by age group

\begin{tabular}{lcccc}
\hline & Late Adolescent (ages 18-21) $(\boldsymbol{n}=\mathbf{7 2})$ & Adult (ages 22-40) $(\boldsymbol{n}=\mathbf{7 0})$ & $\boldsymbol{t}_{\mathbf{( 1 4 0 )}}$ & $\boldsymbol{p}$ value \\
\hline Age (yrs) & $20 \pm 1$ & $27 \pm 5$ & 11.53 & $<0.001$ \\
Education (yrs) & $14 \pm 1$ & $17 \pm 2$ & 11.90 & $<0.001$ \\
Subject Hollingshead SES & $40 \pm 3$ & $47 \pm 7$ & 7.49 & $<0.001$ \\
Parent Hollingshead SES & $54 \pm 9$ & $54 \pm 11$ & 0.13 & $n s$ \\
Sex (\% female) & 53 & 54 & & $n s^{\dagger}$ \\
Ethnicity (\% white) & 62 & 66 & & $n s^{\dagger}$ \\
Black (\%) & 13 & 19 & & $n s^{\dagger}$ \\
Hispanic (\%) & 4 & 4 & $n s^{\dagger}$ \\
Asian (\%) & 14 & 7 & $n s^{\dagger}$ \\
Other/mixed (\%) & 7 & 4 & $n s^{\dagger}$ \\
AUDIT score & $8.9 \pm 6.3$ & $7.2 \pm 4.1$ & 1.99 & 0.049 \\
\hline
\end{tabular}

Values are reported as mean \pm standard deviation. Reported $p$-values reflect the results of unpaired two-tailed comparisons between groups. Exact $p$-values reported unless $p<0.001$. AUDIT, Alcohol Use Disorders Identification Test; SES, socioeconomic status.

${ }^{\dagger} p$-value represents results of $\chi^{2}$ test. 


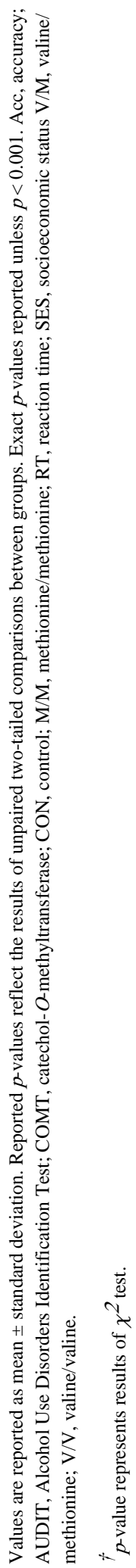

